\title{
Oral Glucose before Venepuncture Relieves Neonates of Pain, but Stress Is Still Evidenced by Increase in Oxygen Consumption, Energy Expenditure, and Heart Rate
}

\author{
KARL BAUER, JÖRG KETTELER, MAGDALENA HELLWIG, MAREN LAURENZ, AND \\ HANS VERSMOLD \\ Department of Pediatrics [K.B.], Klinikum der Johann Wolfgang Goethe-Universität, 60596 Frankfurt, \\ Germany; and Department of Pediatrics [J.K., M.H., M.L., H.V.], Freie Universität Berlin, D-12200
}

Berlin, Germany

\begin{abstract}
ABST
Oral glucose was recommended as pain therapy during
venepuncture in neonates. It is unclear whether this interven-
tion reduces excess oxygen consumption $\left(\dot{V}_{\mathrm{O}_{2}}\right)$, energy loss,
or cardiovascular destabilization associated with venepunc-
ture, and whether $<2 \mathrm{~mL}$ glucose solution is effective. We
tested the hypothesis that oral glucose solution attenuates the
increases in neonatal oxygen consumption, energy expendi-
ture (EE), and heart rate associated with venepuncture for two
different volumes of glucose solution $(2$ and 0.4 mL). In this
prospective, randomized, controlled, double-blind trial, 58
neonates (gestational age, $31-42$ wk; postnatal age, $1-7 \mathrm{~d})$
were randomized to $2 \mathrm{~mL}$ glucose $30 \%, 0.4$ mL glucose $30 \%$,
or 2 mL water by mouth before venepuncture. The videotaped
behavioral pain reactions were scored with the Premature
Infant Pain Profile. Cry duration, $\dot{V}_{2}$, EE (indirect calorim-
etry), and heart rate were measured. The 2 mL glucose
solution reduced pain score and crying after venepuncture
compared with controls $[$ median pain score, 5.5 (interquartile
range, $4-9$ ) versus 11 ( $7-12$ ), $p=0.01$; median duration of
\end{abstract}
first cry, $0 \mathrm{~s}(0-43 \mathrm{~s})$ versus $13 \mathrm{~s}(2-47 \mathrm{~s}), p<0.05$, respectively]. The $0.4 \mathrm{~mL}$ glucose solution had no effect. The $2 \mathrm{~mL}$ glucose solution did not attenuate the $\dot{\mathrm{V}}_{2}$ increase during venepuncture $(1.5 \pm 0.2 \mathrm{~mL} / \mathrm{kg} \min$ (water) versus 1.7 $\pm 0.5(0.4 \mathrm{~mL}$ glucose $)$ versus $1.1 \pm 0.2(2 \mathrm{~mL}$ glucose $)$ (mean $\pm \mathrm{SEM}$ ) nor EE nor heart rate. We conclude that oral administration of $2 \mathrm{~mL}$ glucose $30 \%$ before venepuncture reduced pain expression and crying, but did not prevent the rise in $\dot{\mathrm{V}}_{2}$, EE, or heart rate. Alternative therapies against the stress of nonpainful handling during venepuncture should be explored. (Pediatr Res 55: 695-700, 2004)

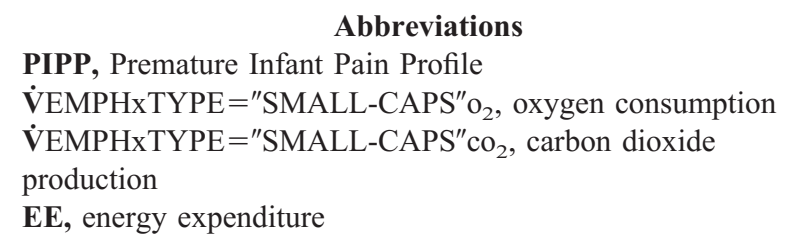

Effective treatment of pain is an important objective of neonatal medicine. A frequently performed painful procedure during neonatal intensive care is blood sampling. The oral application of concentrated sucrose or glucose solutions reduces the behavioral pain reaction (cry, facial reactions) to blood sampling $(1,2)$. But blood sampling also induces an increase in oxygen consumption $\left(\dot{\mathrm{V}}_{2}\right)$, EE, and heart rate (3). To our knowledge, the effect of sweet oral solutions on $\dot{\mathrm{V}}_{2}$ and EE during venepuncture has not been studied and it is controversial whether sweet oral solutions mitigate the

Received April 23, 2003; accepted September 17, 2003.

Correspondence: Karl Bauer, M.D., Professor of Pediatrics, Department of Pediatrics, Klinikum der Johann Wolfgang Goethe-Universität, Theodor-Stern-Kai 7, 60596 Frankfurt, Germany; e-mail: Karl.Bauer@kgu.de

DOI: 10.1203/01.PDR.0000113768.50419.CD increase in heart rate during blood sampling. A reduction in heart rate $(4,5)$ and no effect on heart rate (6) have been reported, and, in a recent meta-analysis, no effect of oral sucrose on heart rate could be demonstrated (1).

There is uncertainty about the optimal effective volume of the sugar solution (1). Most investigators used an absolute volume of $2 \mathrm{~mL}$, but an effect has been reported with a volume as low as 0.05 $\mathrm{mL}$ (6). A reduction in the volume seems desirable to facilitate application, especially in preterm neonates.

We therefore designed this randomized controlled trial of oral glucose $30 \%$ solution given before venepuncture in neonates to test the hypothesis that oral glucose solution attenuates the increases in neonatal oxygen consumption, EE, and heart rate associated with venepuncture for two different volumes of glucose solution $(2 \mathrm{~mL}$ and $0.4 \mathrm{~mL})$. 


\section{PATIENTS AND METHODS}

\section{Patients and Sample Size}

Neonates born at our institution were eligible for the study if they fulfilled the following inclusion criteria: 1) gestational age $\geq 30 \mathrm{wk}, 2$ ) postnatal age between $12 \mathrm{~h}$ and $8 \mathrm{~d}, 3$ ) venepuncture at the back of the hand indicated as part of the routine medical care scheduled at $1200 \mathrm{~h}$ or $1500 \mathrm{~h}$, 4) spontaneous respiration in room air, 5) clinically stable, 6) no neurologic impairment, 7) receiving no other analgesics or sedatives that would alter the response to a painful stimulus, and 8) informed parental consent. The primary outcome measure was $\dot{\mathrm{V}}_{2}$. We chose a reduction of $\dot{\mathrm{V}}_{2}$ by $20 \%$ in neonates receiving oral glucose as clinically significant and calculated that 20 subjects in each group were necessary to reject the null hypothesis, with a type I error of $5 \%$ and a type II error of $20 \%$ (power $80 \%$ ).

The study was approved by the hospital's institutional review board and written parental informed consent was obtained for each infant.

\section{Methods}

Indirect calorimetry. We measured $\dot{\mathrm{V}}_{2}$ and $\dot{\mathrm{V}}_{\mathrm{CO}_{2}}$ with an open circuit flow-through calorimeter (Datex Deltatrac II, Datex-Ohmeda Instrumentarium, Helsinki, Finland). It contains a paramagnetic oxygen sensor and an infrared absorption $\mathrm{CO}_{2}$ analyzer, both with an accuracy of $0.01 \%$. We have modified and validated this device for use in preterm and term neonates (7). During the measurements in the spontaneously breathing neonates, exhaled gas was collected in a small transparent face mask (volume $40 \mathrm{~mL}$ ) held close in front of the neonate's mouth and nose without actually touching the skin. A bedside observer followed the infant's movements with the mask to ensure that it always covered the infant's mouth and nose. A continuous flow of $6 \mathrm{~L}$ air per minute passed through the face mask to the calorimeter. This ensured complete collection of the exhaled gas. It took the gas 2 min to travel the distance between the neonate and the gas analyzer, resulting in a reaction time of $2 \mathrm{~min}$ of our system. We accounted for the response time of the calorimeter and documented each $\dot{\mathrm{V}}_{2}$ value at its respective sampling time. Before each measurement, the calorimeter was calibrated in room air and in a calibration gas $\left(5 \% \mathrm{CO}_{2}, 95 \% \mathrm{O}_{2}\right)$. The measurement error calculated from quantitative combustion of methanol was $1 \pm$ $2 \%$. $\dot{\mathrm{V}}_{2}$ and $\dot{\mathrm{V}}_{\mathrm{CO}_{2}}$ were measured every minute. The lower limit for accurate measurements of $\dot{\mathrm{V}}_{2}$ and $\dot{\mathrm{V}}_{\mathrm{CO}_{2}}$ with our system was $1.4 \mathrm{~mL} / \mathrm{min}$. EE was calculated from $\dot{\mathrm{V}}_{2}$ and $\dot{\mathrm{V}}_{\mathrm{CO}_{2}}$ with the equation: $\mathrm{EE}(\mathrm{J} / \mathrm{kg} / \mathrm{min})=16 \times \dot{\mathrm{V}}_{\mathrm{O}_{2}}(\mathrm{~mL} / \mathrm{min})+5$ $\times \dot{\mathrm{V}}_{\mathrm{CO}_{2}}(\mathrm{~mL} / \mathrm{min})$.

Heart rate. We continuously measured heat rate with an ECG monitor and oxygen saturation by pulse oxymetry (HPCMS monitor; Hewlett-Packard, Böblingen, Germany).

PIPP. The PIPP score has been designed and validated to assess acute pain in preterm and term neonates (8). It is calculated from seven different items, each graded from 0 to 3 . Two items describe baseline characteristics of the neonate (gestational age and behavioral state before the painful event), two items are derived from physiologic measurements (heart rate and oxygen saturation), and three items describe facial movements (brow bulge, eye squeeze, and nasolabial furrow). The last five items are assessed as changes from baseline during successive observation periods of $30 \mathrm{~s}$. Validity and inter- and intra-rater reliability have been demonstrated for use in the clinical setting $(8,9)$. The maximum PIPP score is 21 for preterm infants and 18 for term infants. A total PIPP score of 6 or less generally indicates minimal or no pain. The facial responses were recorded with a digital camera with real-time counter. The stages of the procedure were identified by voice as they occurred and also recorded on the videotape. The recordings were analyzed using slow motion and stop-frame playback technique by the same rater (J.K.), who was unaware of the treatment assignment.

Crying time. We recorded the length of the latency period until crying started after skin puncture; the duration of the first cry, defined as continuous audible vocalizations beginning with the venepuncture until a quiet interval of $5 \mathrm{~s}$; and the percentage of time spent crying in the first $5 \mathrm{~min}$ after venepuncture (10).

\section{Study Protocol}

After parental consent was obtained, the infants were randomly assigned to one of three interventions: 1) $2 \mathrm{~mL}$ oral glucose $30 \%(0.6 \mathrm{~g}), 2) 0.4 \mathrm{~mL}$ oral glucose $30 \%(0.12 \mathrm{~g})$, and 3) $2 \mathrm{~mL}$ sterile water. The treatment assignment code was generated from a table of random numbers. The treatment allocation was sealed in an opaque envelope. Randomization and application of the study solution was performed by a person not involved in the subsequent measurements. Codes of allocation were broken only after the inclusion of the last neonate.

Neonates were routinely cared for in 3-h intervals. When a venepuncture was scheduled, ECG electrodes and the pulse oximetry sensor were placed in the care period preceding the venepuncture. The study began after the infant had rested for about $2.5 \mathrm{~h}$. The infants were studied lying supine in the incubator $(n=28)$ or open crib $(n=30)$ in which they were normally cared for. The total study period was $30 \mathrm{~min}$. $\dot{\mathrm{V}}_{2}$, $\dot{\mathrm{V}}_{\mathrm{CO}_{2}}$, heart rate, and oxygen saturation were recorded every minute. After $13 \mathrm{~min}$ of recording, the oral solution was delivered from a graded syringe through a small tube onto the tip of the infant's tongue. When the infant started licking and swallowing, the rest of the solution was slowly given to ensure that all solution was taken by the infant. Administration of the solution had to be completed in $1 \mathrm{~min}$. The infant's hand was then cleaned with an alcohol swab and prepared for venepuncture. Two minutes after the beginning of the application of the oral solution, the venepuncture was performed with a 20 -gauge needle on the dorsum of the right or left hand by the doctor on clinical duty, who was unaware of the neonate's group assignment. If no blood was immediately obtained, repositioning of the needle was allowed for $60 \mathrm{~s}$. If the puncture was still unsuccessful, the needle was left in place and the procedure was continued as if the puncture had been successful, with gentle squeezing of the infant's hand. The needle was removed 3 min after the puncture and a bandage was applied to the 
neonate's hand. During the puncture and the subsequent 12min recovery period no other comforting treatment (pacifier, words, or touches) was used.

$\dot{\mathrm{V}}_{2}$ and $\dot{\mathrm{V}}_{\mathrm{CO}_{2}}$ were measured every minute from the start of the baseline period until the end of the recovery period. The measurements during the $3 \mathrm{~min}$ after the application of the oral solution were discarded because, for this procedure, the face mask had to be lifted a little further away from the neonate's face, potentially resulting in an incomplete collection of the infant's breath. Heart rate and oxygen saturation were measured throughout the study period. The PIPP score was obtained in ten 30-s periods starting from the moment of venepuncture and continuing for $5 \mathrm{~min}$ and at 8 and $10 \mathrm{~min}$ after venepuncture.

\section{Data Analysis}

To allow statistical testing of differences in $\dot{\mathrm{O}}_{2}$, EE, heart rate, and PIPP in addition to plotting those variables against time, three observation periods were defined: 1) baseline: the values measured from min 10 to 5 before venepuncture; 2) venepuncture: the values of $\min 1,2$, and 3 after venepuncture; and 3) recovery: the last 5 min of the study. Mean values for each period were calculated for $\dot{\mathrm{V}}_{2}$ and heart rate and median values for the PIPP score. The increase in heart rate or in $\dot{\mathrm{V}}_{2}$ was calculated as difference in mean heart rate or $\dot{\mathrm{V}}_{2}$ between baseline and venepuncture.

\section{Statistical Analysis}

Statistical analysis was performed with SPSS 11.0 software (SPSS, Inc., Chicago, IL, U.S.A.). Continuous data are presented as mean \pm SEM. Differences between groups were tested with one-way ANOVA with post hoc analysis by the Tukey test. Mean values of $\dot{\mathrm{V}}_{2}$ and heart rate over time within each group were compared using one-way ANOVA with repeated measures. Ordinal data are presented as median and interquartile range. Differences between groups were tested with the Kruskal-Wallis one-way ANOVA; differences between time periods were tested with the Wilcoxon signed rank test. Values of $p<0.05$ were considered statistically significant.

\section{RESULTS}

Patients. Sixty neonates were randomized during the 8-mo observation period; two measurements had to be excluded from further analysis because of incomplete data. The three treatment groups were comparable with regard to baseline clinical data and postnatal age when the study was performed (Table 1).

PIPP score. The PIPP scores $1 \mathrm{~min}$ before venepuncture were similar in all three groups - the neonates showed no expression of pain. The PIPP scores in the first minutes after the venepuncture were markedly higher than at baseline and returned to baseline level at the end of the recovery period (Fig. 1). The highest median PIPP scores during venepuncture were found in the control group. They were significantly higher than in the $2 \mathrm{~mL}$ glucose group (Table 2).

Crying. The analysis of crying characteristics consistently indicated an analgesic effect of $2 \mathrm{~mL}$ glucose, but no effect of $0.4 \mathrm{~mL}$ glucose. Fifty percent of the neonates in the $2 \mathrm{~mL}$ glucose group did not cry at all in the first $5 \mathrm{~min}$ after venepuncture compared with only $10 \%$ in the control group. The duration of first cry and the percentage of time spent crying in the first 5 min after venepuncture were significantly reduced in the $2 \mathrm{~mL}$ glucose group, and the latency period until crying started after venepuncture was significantly longer (Table 2).

Oxygen consumption and energy expenditure. The changes in mean $\dot{\mathrm{V}}_{2}$ over time during the total study period are shown in Figure $2 \mathrm{~A}$. $\dot{\mathrm{V}}_{2}$ values measured during the last $3 \mathrm{~min}$ before venepuncture had to be discarded for methodological reasons. $\dot{\mathrm{V}}_{2}$ was increased after venepuncture in all three groups and returned to baseline after about $10 \mathrm{~min}$. We compared mean $\dot{\mathrm{V}}_{2}$ and EE during baseline, venepuncture, and recovery period. $\dot{\mathrm{V}}_{2}$ and $\mathrm{EE}$ at baseline were not different between groups. $\dot{\mathrm{V}}_{2}$ and EE during venepuncture were higher than at baseline in all three groups (Table 3). The increase in $\dot{\mathrm{V}}_{2}$ between baseline and venepuncture period was not statistically different: $\dot{\mathrm{V}}_{2}$ increased by $1.5 \pm 0.2 \mathrm{~mL} / \mathrm{kg} / \mathrm{min}$ (mean $\pm \mathrm{SEM}$ ) in the control group, by $1.7 \pm 0.5 \mathrm{~mL} / \mathrm{kg} / \mathrm{min}$ in the $0.4 \mathrm{~mL}$ glucose group, and by $1.1 \pm 0.2 \mathrm{~mL} / \mathrm{kg} / \mathrm{min}$ in the $2 \mathrm{~mL}$ glucose group ( $p=0.287$, ANOVA).

Table 1. Patient characteristics

\begin{tabular}{lccc}
\hline & Controls & $0.4 \mathrm{~mL}$ Glucose & $2 \mathrm{~mL}$ Glucose \\
\hline Patients $(n)$ & 20 & 20 & 18 \\
Gestational age (wk) & $35(32-41)$ & $39(31-41)$ & $35(30-42)$ \\
Birth weight $(\mathrm{g})$ & $2285(1314-4040)$ & $2680(1300-4070)$ & $2590(1106-4340)$ \\
5-min Apgar & $9.5(5-10)$ & $10(7-10)$ & $9(7-10)$ \\
10-min Apgar & $10(8-10)$ & $10(9-10)$ & $10(8-10)$ \\
Postnatal age $(\mathrm{d})$ & $3(1-6)$ & $2(1-7)$ & $2.5(1-7)$ \\
Neonates studied at a postnatal & $8(40 \%)$ & $7(35 \%)$ & $5(28 \%)$ \\
$\quad$ age $\leq 48 \mathrm{~h}(\mathrm{n})$ & $2275(1212-3960)$ & $2620(1330-4010)$ & $2485(1028-4200)$ \\
Body weight $(\mathrm{g})$ & $3.5(2-6)$ & $3(2-6)$ & $3(2-5)$ \\
Painful procedures before study** & $183(65-272)$ & $136(31-254)$ & $167(80-222)$ \\
Duration of venepuncture (s) & & &
\end{tabular}

Data are median (range).

** Associated with skin punctures (blood sampling, intravenous line insertion, lumbar puncture). 


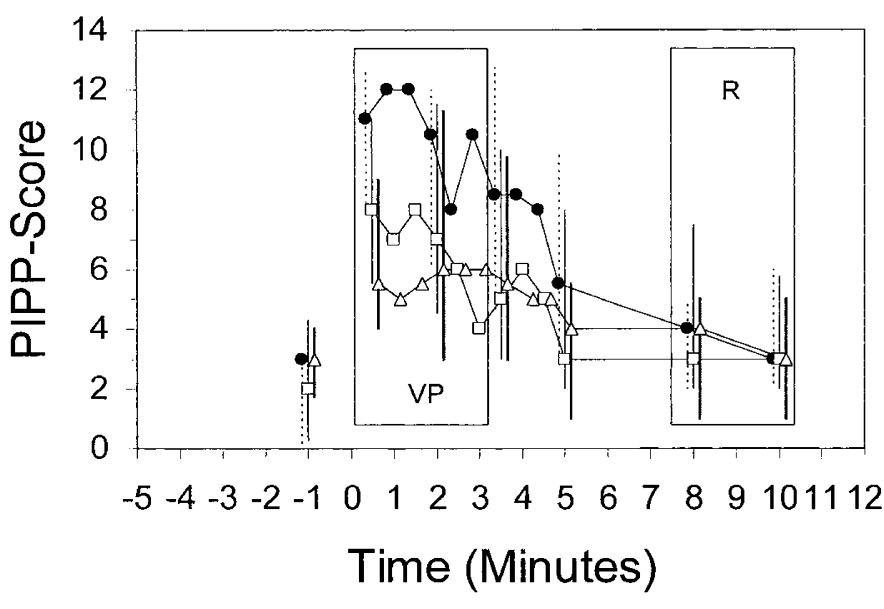

Figure 1. Changes in median PIPP Scores over time in the water group (closed circles), the $0.4 \mathrm{~mL}$ glucose group (open squares), and in the $2 \mathrm{~mL}$ glucose group (open triangles). Zero time is the moment of skin puncture. Bars mark the time periods used to calculate PIPP scores during the venepuncture $(V P)$, and recovery $(R)$ periods. Data are median and interquartile range. To improve legibility, interquartile ranges are depicted only for every third value.

Heart rate. The minute-to-minute changes in mean heart rate during the study are shown in Figure $2 B$. Heart rate already increased during the application of the oral solution and the preparation for venepuncture $(-2,-1$, and $0 \mathrm{~min})$, peaked during venepuncture, and returned to baseline $10 \mathrm{~min}$ later. This time course of heart rate changes was nearly identical in the three groups. The mean heart rate during the venepuncture was markedly higher than at baseline in all three groups (Table 3). There was no difference in the mean increase in heart rate between baseline and venepuncture between the groups: heart rate increased by $23 \pm 4$ beats per minute (mean \pm SEM) in the control group, by $19 \pm 3$ beats per minute in the $0.4 \mathrm{~mL}$ glucose group, and by $17 \pm 5$ beats per minute in the $2 \mathrm{~mL}$ glucose group ( $p=0.607$, ANOVA).

\section{DISCUSSION}

In this randomized controlled trial of pain therapy with oral glucose, we demonstrated that $2 \mathrm{~mL}$ glucose $30 \%$ given before venepuncture reduced immediate behavioral responses and crying after the acute pain, but did not attenuate the increases in $\dot{\mathrm{V}}_{2}, \mathrm{EE}$, and heart rate that are associated with the painless but stressful handling during venepuncture. Thus, venepuncture remains a stressful procedure for the neonate despite the application of oral glucose.

It is of therapeutic relevance to study pain therapy for venepuncture in neonates because it is a painful procedure and is performed frequently during intensive care. Furthermore, neonates are more sensitive to cutaneous stimuli than adults (11) and repeated skin punctures affect their subsequent pain perception (12) and their behavioral and autonomic pain reactions (13). Solutions of sucrose, glucose, or artificial sweetener given orally before blood sampling are effective in reducing facial and vocal reactions to pain $(1,2,14)$. The sweet sensory stimulus results in an analgesic effect lasting for about $10 \mathrm{~min}$, i.e. well beyond the end of the administration of the sweet
Table 2. Analysis of PIPP score and crying

\begin{tabular}{|c|c|c|c|}
\hline & Controls & $0.4 \mathrm{~mL}$ Glucose & $2 \mathrm{~mL}$ Glucose \\
\hline \multicolumn{4}{|l|}{ PIPP score* } \\
\hline Baseline & $3(0-3)$ & $2(0-2)$ & $3(1-4)$ \\
\hline Venepuncture & $11(7-12) \ddagger$ & $7(4-11) \ddagger$ & $5.5(4-9) \div \S$ \\
\hline Recovery & $4(3-7)$ & $3(2-6.5)$ & $4(1-5)$ \\
\hline \multicolumn{4}{|l|}{ Cry analysis* } \\
\hline Duration of first cry (s) & $13(2-47)$ & $18(4-88)$ & $0(0-43) \dagger$ \\
\hline Percentage crying (\%) & $11(1-30)$ & $9(1-42)$ & $0(0-15) \dagger$ \\
\hline Latency period $(\mathrm{s})^{* *}$ & $2(0-129)$ & $2(0-32)$ & $300(1-300) \dagger$ \\
\hline
\end{tabular}

Median values of the PIPP score during the three observation periods (baseline, venepuncture, recovery) for the study groups. Median values of duration of first cry (s), percentage of time spent crying in the first 5 min after venepuncture, and duration of the latency period between venepuncture and start of crying (s) for the study groups.

* Median (interquartile range).

$\ddagger p<0.001$, venepuncture $v$ s baseline (Wilcoxon signed rank test).

$\S p=0.01,2 \mathrm{~mL}$ glucose $v s$ controls (Kruskal-Wallis one-way ANOVA).

$\dagger p<0.05,2 \mathrm{~mL}$ glucose $v s$ controls (Kruskal-Wallis one-way ANOVA).

** Latency period in infants who did not cry at all in the first 5 min was set at $300 \mathrm{~s}$.

solution. Naltrexone can reverse the antinociceptive effects of sucrose in rats (15), and sucrose is not effective in human neonates born to mothers who received methadone during pregnancy (16). Both observations support the hypothesis that the analgesic effect of sweet solutions is mediated by the release of endogenous endorphins.

Previous studies have been criticized for short observation periods, insufficient standardization of the procedure, and small sample size (1). Therefore, we continuously recorded parameters for $30 \mathrm{~min}$ and consider it a strength of our study that we present $\dot{\mathrm{V}}_{2}$ and EE from baseline to the end of the recovery period minute-to-minute so that the reader can judge the appropriateness of our selection of study periods for which mean values were calculated and how they relate to the rest of the observation period. We standardized the procedure to ensure that the stimulus was comparable in intensity and duration and to minimize context influences from comforting co-interventions on the neonatal response, and calculated a sufficient sample size. In the majority of previous studies, the effect of sucrose during a heel-stick was studied. We decided to study the effect of glucose solution during venepuncture. Glucose has the same analgesic effect as sucrose (2), but, contrary to sucrose, glucose is widely used in neonatal care as an intravenous or oral solution, it is more readily available in a hospital, and it does not contain fructose. We studied its effect during venepuncture because venepuncture, which is less painful than a heel-stick (17), is our preferred method of blood sampling.

We found that $2 \mathrm{~mL}$ glucose $30 \%$ significantly reduced the immediate behavioral pain response rated with the PIPP score and shortened crying after venepuncture compared with controls. However, the smaller volume of $0.4 \mathrm{~mL}$ glucose $30 \%$ that we tested to determine whether a volume reduction was possible did not reduce the PIPP score nor the crying time. The influence of the volume of sweet oral solutions on their analgesic effect is unclear. In the majority of studies, an absolute volume of $2 \mathrm{~mL}$ sucrose solution was used but effects have been reported for volumes as low as $0.05 \mathrm{~mL}$ (6). For glucose 

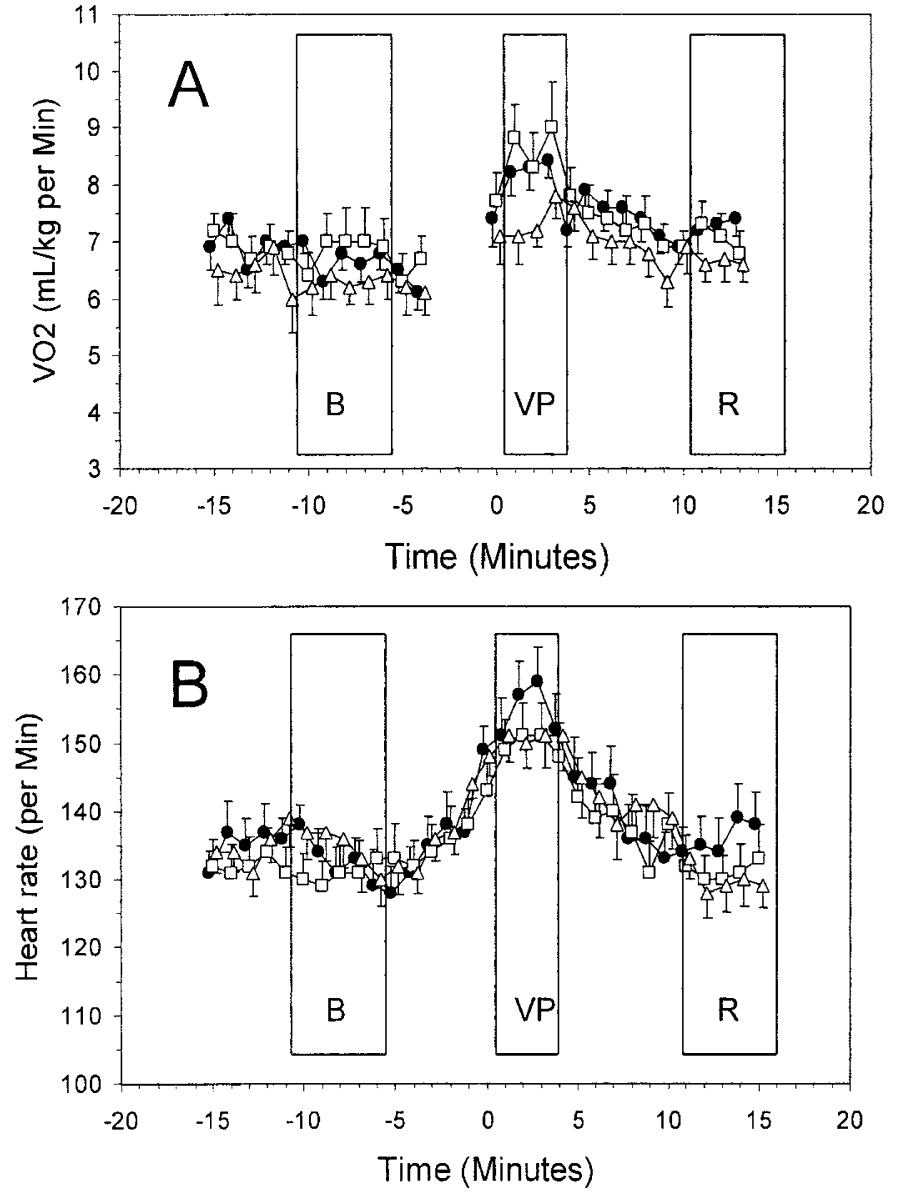

Figure 2. Changes in $\dot{\mathrm{V}}_{2}(A)$ and heart rate $(B)$ over time in the water group (closed circles), the $0.4 \mathrm{~mL}$ glucose group (open squares), and in the $2 \mathrm{~mL}$ glucose group (open triangles). Zero time is the moment of skin puncture. Bars mark the time periods used to calculate mean $\dot{V}_{O_{2}}$ for the baseline $(B)$, venepuncture $(V P)$, and recovery $(R)$ periods. $\dot{V}_{\mathrm{O}_{2}}$ values measured during the last $3 \mathrm{~min}$ before venepuncture had to be discarded for methodological reasons. Values are mean \pm SEM.

solutions, effects have been reported for a volume of $2 \mathrm{~mL}(2)$. A $1 \mathrm{~mL}$ glucose solution was effective in one study (5) but ineffective in another (18). By increasing the volume of sweet oral solution, the duration of the sweet stimulus can be prolonged. Thus, we speculate that $0.4 \mathrm{~mL}$ were much less effective than $2 \mathrm{~mL}$ because the sweet stimulus was shorter. This explanation is supported by the finding that prolonging the sweet stimulus by repeated doses of $0.05 \mathrm{~mL}$ sucrose $24 \%$ (10) or $1 \mathrm{~mL}$ glucose $30 \%$ (18) were more effective than a single dose. In addition to the duration of the stimulus, more intense sweetness also increases effectiveness. Sucrose has an effect at concentrations of more than $12 \%$ (19), glucose at concentrations of more than $10 \%$ (5). Therefore, in clinical trials, $25 \%$ sucrose or $30 \%$ glucose solutions have been used. No gastrointestinal side effects for the single use of these concentrated sugar solutions have been reported so far (1)

In contrast to the mitigation of the behavioral and vocal pain reactions after venepuncture, $2 \mathrm{~mL}$ glucose did not attenuate the increases in $\dot{\mathrm{V}}_{2}, \mathrm{EE}$, and heart rate. These increases result from the unrest and motor activity induced by the painless handling associated with venepuncture in addition to the acute
Table 3. Mean values of $\mathrm{VO}_{2}$, energy expenditure, and heart rate during the three observation periods (baseline, venepuncture, recovery) for the study groups

\begin{tabular}{llll}
\hline & Controls & $0.4 \mathrm{~mL}$ Glucose $2 \mathrm{~mL}$ Glucose \\
\hline $\mathrm{VO}_{2}(\mathrm{~mL} / \mathrm{kg} / \mathrm{min}) \dagger$ & & & \\
$\quad$ Baseline & $6.7 \pm 0.2$ & $6.9 \pm 0.5$ & $6.3 \pm 0.4$ \\
$\quad$ Venepuncture & $8.2 \pm 0.3 \ddagger$ & $8.6 \pm 0.6 \ddagger$ & $7.4 \pm 0.3 \ddagger$ \\
$\quad$ Recovery & $7.3 \pm 0.3$ & $7.1 \pm 0.4$ & $6.8 \pm 0.3$ \\
Energy expenditure $(\mathrm{J} / \mathrm{kg} / \mathrm{min}) \dagger$ & & & \\
$\quad$ Baseline & $139 \pm 5$ & $138 \pm 8$ & $129 \pm 9$ \\
$\quad$ Venepuncture & $171 \pm 7 \ddagger$ & $173 \pm 13 \ddagger$ & $150 \pm 7 \ddagger$ \\
$\quad$ Recovery & $148 \pm 5$ & $142 \pm 7$ & $139 \pm 8$ \\
Heart rate (per min $) \dagger$ & & & \\
$\quad$ Baseline & $133 \pm 3$ & $131 \pm 4$ & $134 \pm 4$ \\
$\quad$ Venepuncture & $156 \pm 4 \$$ & $150 \pm 5 \ddagger$ & $151 \pm 3 \ddagger$ \\
$\quad$ Recovery & $134 \pm 4$ & $132 \pm 4$ & $129 \pm 3$ \\
\hline
\end{tabular}

$\dagger$ Mean \pm SEM

$\ddagger p<0.01$, venepuncture $v s$ baseline (repeated measures ANOVA and Tukey's test).

pain stimulus or signify a stress response that was not influenced by an analgesic alone. It is especially relevant to prevent excess $\dot{\mathrm{V}}_{2}$ and $\mathrm{EE}$ in sick or preterm neonates with respiratory problems or when the provision of an adequate caloric intake is difficult. The effects of sweet oral solutions on $\dot{\mathrm{V}}_{2}$ or EE during venepuncture have not been studied previously.

We measured $\dot{\mathrm{V}}_{2}$ and EE with a system we had previously validated for use in neonates (7). The advantages of our system are that routine care can continue, and no increase in activity or body temperature is induced by the measurement procedure. The face mask used for the measurements was transparent and allowed the observation of the neonate's facial actions with the mask in place. It did not influence the facial expressions because it did not touch the face. A limitation of our measurement procedure was that the mask had to be lifted from the infant's face during the application of the oral solution and thus values during the following $3 \mathrm{~min}$ had to be excluded to avoid artifacts by incomplete breath sampling. Yet, $\dot{\mathrm{V}}_{2}$ could be measured during the important time of the acute pain reaction immediately after the skin puncture.

Venepuncture increased $\dot{\mathrm{V}}_{2}$ in all groups, and mean $\dot{\mathrm{V}}_{2}$ values of the groups after venepuncture were not significantly different. We had an adequate number of patients in our study to detect a $>20 \%$ difference in $\dot{\mathrm{V}}_{2}$ between the three groups with an $\alpha$ error of 0.05 and a $\beta$ error of 0.2 . The $16 \%$ increase of $\dot{\mathrm{V}}_{2}$ from baseline that we observed in the $2 \mathrm{~mL}$ glucose group was similar to the $13 \%$ increase that was reported for neonates after a nonpainful cold stimulus (20). This suggests that the major proportion of the $\dot{\mathrm{V}}_{2}$ increase during venepuncture is caused by the nonpainful handling and therefore cannot be influenced by pain therapy. Similarly, no effect of local anesthesia before lumbar puncture on heart rate and respiratory rate has been found in neonates because this pain therapy did not reduce but even increased handling during the procedure (21).

Venepuncture increased heart rate to a similar degree in all groups. With our continuous minute-by-minute recordings we demonstrated that heart rate already increased during the painless application of the oral solution and the preparation for venepuncture and that this increase persisted longer than the acute pain behavior. Previous studies of heart rate during 
venepuncture and pain therapy with sweet oral solutions were limited by recording only data for a few isolated time points and by incomplete reporting of the variability of the data. Thus, only two studies of heart rate could be combined in a metaanalysis (1), which did not show an effect of sucrose solution on the heart rate response. A sucrose solution that reduced a facial pain score during heel stick had no effect on cardiac autonomic reactivity (22).

Our results that oral glucose reduced PIPP score but did not reduce excess $\dot{\mathrm{V}}_{2}$, EE, and heart rate disclose a limitation of composite pain scores, like the PIPP, which have been regarded as the most valid representations of the neonatal pain reaction (23): composite pain scores encompassing behavioral and physiologic items cannot recognize the discordant effects of sweet oral solutions on behavioral and physiologic reactions to blood sampling because they are calculated as the sum of behavioral and physiologic reactions. It was previously observed that the concordance between behavioral and physiologic reactivity is only modest in neonates after heel lancing without pain therapy (24). With our study design it was possible to demonstrate that pain therapy with oral glucose solution accentuated the discordance between behavioral and physiologic reactivity by attenuating the behavioral response but leaving the physiologic response unchanged.

\section{CONCLUSION}

We conclude that $2 \mathrm{~mL}$ oral glucose $30 \%$ was an effective pain therapy for venepuncture in neonates and mitigated the behavioral and vocal responses to acute pain. But even with the use of oral glucose, venepuncture remained a stressful procedure for neonates with excess $\dot{\mathrm{V}}_{2}$ and EE. Therefore, minimal handling and the reduction of blood sampling to the absolute minimum are still valid principles of neonatal care. We recommend that co-interventions for use in combination with sweet oral solutions, like sucking on a pacifier $(2,25)$, simulated rocking on an oscillating mattress (6), or multisensory stimulation (18), should be explored for their potential to reduce the nonpainful stress of venepuncture.

\section{REFERENCES}

1. Stevens B, Yamada J, Ohlsson A 2003 Sucrose for analgesia in newborn infants undergoing painful procedures (Cochrane Review). In: The Cochrane Library, Issue 1. Oxford, U.K., Update Software Ltd.
2. Carbajal R, Chauvet X, Couderc S, Olivier-Martin M 1999 Randomised trial of analgesic effects of sucrose, glucose, and pacifiers in term neonates. BMJ 319:13931397

3. Yeh TF, Lilien LD, Leu ST, Pildes RS 1984 Increased oxygen consumption and energy loss in premature infants following medical care procedures. Biol Neonate 46:157-162

4. Bucher HU, Moser T, von Siebenthal K, Keel M, Wolf M, Duc G 1995 Sucrose reduces pain reaction to heel lancing in preterm infants: a placebo-controlled randomised and masked study. Pediatr Res 38:332-335

5. Skogsdal Y, Eriksson M, Schollin J 1997 Analgesia in newborns given oral glucose. Acta Paediatr 86:217-220

6. Johnston CC, Stremler RL, Stevens BJ, Horton LJ 1997 Effectiveness of oral sucrose and simulated rocking on pain response in preterm neonates. Pain 72:193-199

7. Bauer K, Pasel K, Uhrig C, Sperling P, Versmold H 1997 Comparison of face mask, head hood and canopy for breath sampling in flow-through indirect calorimetry to measure $\mathrm{VO}_{2}$ and $\mathrm{VCO}_{2}$ of preterm infants $<1500 \mathrm{~g}$. Pediatr Res 41:139-144

8. Stevens B, Johnston C, Petryshen P, Taddio A 1996 Premature infant pain profile: development and initial validation. Clin J Pain 12:13-22

9. Ballantyne M, Stevens B, McAllister M, Dionne K, Jack A 1999 Validation of the premature infant pain profile in the clinical setting. Clin J Pain 15:297-303

10. Johnston CC, Stremler R, Horton L, Friedman A 1999 Effect of repeated doses of sucrose during heel stick procedure in preterm neonates. Biol Neonate 75:160-166

11. Andrews K, Fitzgerald M 1999 Cutaneous flexion reflex in human neonates: a quantitative study of threshhold and stimulus-response characteristics after single and repeated stimuli. Dev Med Child Neurol 41:696-703

12. Taddio A, Shah V, Gilbert-McLeod C, Katz J 2002 Conditioning and hyperalgesia in newborns exposed to repeated heel lances. JAMA 288:857-861

13. Grunau RE, Oberländer T, Whitfield MF, Fitzgerald C, Lee SK 2001 Demographic and therapeutic determinants of pain reactivity in very low birth weight neonates at 32 weeks postconceptual age. Pediatrics 107:105-112

14. Ramenghi LA, Griffith GC, Wood CM, Levene MI 1996 Effect of non-sucrose sweet tasting solution on neonatal heel prick response. Arch Dis Child 74:F129-F131

15. Shide DJ, Blass EM 1989 Opioidlike effects of intraoral infusions of corn oil and polycose on stress reactions in 10-day-old rats. Behav Neurosci 103:1168-1175

16. Blass EM, Ciaramitaro V 1994 A new look at some old mechanisms in human newborns: taste and tactile determinants of state, affect, and action. Monogr Soc Res Child Dev 59:1-81

17. Larsson BA, Tannfeldt G, Lagercrantz H, Olsson GL 1998 Venipuncture is more effective and less painful than heel lancing for blood tests in neonates. Pediatrics 101:882-886

18. Bellieni CV, Bagnoli F, Perrone S, Nenci A, Cordelli DM, Fusi M, Ceccarelli S, Bounocore G 2002 Effect of multisensory stimulation on analgesia in term neonates: a randomized controlled trial. Pediatr Res 51:460-463

19. Haouari N, Wood C, Griffith G, Levene M 1995 The analgesic effect of sucrose in full term infants: a randomised controlled trial. BMJ 310:1498-1500

20. Rao M, Blass EM, Brignol MM, Marino L, Glass L 1997 Reduced heat loss following sucrose ingestion in premature and normal human newborns. Early Hum Dev 48:109-116

21. Porter FL, Miller JP, Cole FS, Marshall RE 1991 A controlled clinical trial of local anesthesia for lumbar punctures in newborns. Pediatrics 88:663-669

22. Oberländer T, Grunau RE, Hiddink F, Maaskant R, Fitzgerald CE, Ling E, Whitfield MF 2002 Oral sucrose in the preterm infant: analgesic or behavioural modifier? Pediatr Res 51(suppl 4):44A(abstr)

23. Abu-Saad HH, Bours GJJW, Stevens B, Hamers PH 1998 Assessment of pain in the neonate. Semin Perinatol 22:402-416

24. Morison SJ, Grunau RE, Oberlander TF, Whitfield MF 2001 Relations between behavioural and cardiac autonomic reactivity to acute pain in preterm neonates. Clin J Pain 17:350-358

25. Blass EM, Watt LB 1999 Suckling- and sucrose-induced analgesia in human newborns. Pain 83:611-623 